\title{
Single-level anterior cervical discectomy and interbody fusion using PEEK anatomical cervical cage and allograft bone
}

\author{
C. Faldini $\cdot$ M. Chehrassan $\cdot$ M. T. Miscione $\cdot$ \\ F. Acri • M. d'Amato $\cdot$ C. Pungetti • \\ D. Luciani $\cdot$ S. Giannini
}

Received: 25 October 2011/Accepted: 26 October 2011/Published online: 17 November 2011

(C) The Author(s) 2011. This article is published with open access at Springerlink.com

\begin{abstract}
Background In an effort to avoid the morbidity associated with autogenous bone graft harvesting, cervical cages in combination with allograft bone are used to achieve fusion. The goal of the current study was to assess the reliability and efficacy of anterior cervical discectomy and interbody fusion (ACDF) using a PEEK anatomical cervical cage in the treatment of patients affected by singlelevel cervical degenerative disease.

Methods and materials Twenty-five patients affected by single-level cervical degenerative pathology between $\mathrm{C} 4$ and C7 were enrolled in this study. The clinical findings were assessed using the Neck Disability Index and the Visual Analog Scale. Surgical outcomes were rated according to Odom's criteria at last follow-up. Fusion was graded as poor, average, good or excellent by assessing the radiographs. Cervical spine alignment was evaluated by sagittal segmental alignment and sagittal alignment of the whole cervical spine preoperatively, 6 months postoperatively and at the last follow-up.

Results Twenty-five patients underwent ACDF using a PEEK anatomical cervical cage. All patients had a minimum 2 years of follow-up. The operative levels were C4-C5 in 5 patients, C5-C6 in 12 patients and C6-C7 in 8 patients. Preoperatively, average NDI was 34, 13 at 6 months, and 10 at latest follow-up. The mean preoperative VAS was 7; the mean postoperative VAS at latest follow-up was 3. Good or excellent fusion was achieved in all patients within 10 months (mean 5 months). Preoperatively, average
\end{abstract}

C. Faldini $(\bowtie) \cdot$ M. Chehrassan - M. T. Miscione - F. Acri · M. d'Amato - C. Pungetti - D. Luciani - S. Giannini Department of Orthopaedic Surgery, Istituto Ortopedico Rizzoli, University of Bologna, Via G.C. Pupilli 1, 40136 Bologna, Italy e-mail: cesare.faldini@ior.it sagittal segmental alignment (SSA) was $0.2^{\circ}$ and average sagittal alignment of the cervical spine (SACS) $15.8^{\circ}$. Six months after surgery, average SSA was $1.8^{\circ}$ and average SACS $20.9^{\circ}$, and at last follow-up, average SSA was $1.6^{\circ}$ and average SACS $18.5^{\circ}$.

Conclusion Anterior cervical discectomy and interbody fusion using PEEK anatomical cervical cages can be considered a safe and effective technique to cure cervical disc herniation with intractable pain or neural deficit in cases where conservative treatment failed.

Keywords ACDF - PEEK cage - Allograft bone

\section{Introduction}

Degenerative disease of the cervical spine is a common cause of neck and upper limb pain which, in severe cases, could potentially be a debilitating disease. In addition to agerelated degenerative changes, there are many other conditions that could lead to degenerative changes at the level of the cervical spine $[8,18,36]$. Several procedures have been described for the treatment of disc herniation and cervical spondylosis when conservative treatment fails, including anterior decompression, laminectomy, laminoplasty and instrumented anterior and posterior fusion by plates or screws $[2,3,5,6,10,13,14,21,22,24,39]$. Anterior cervical discectomy and interbody fusion (ACDF) is a surgical technique used to treat a variety of cervical spine disorders, such as nerve root or spinal cord compression, cervical spondylosis, and cervical spinal stenosis $[9,15]$. The anterior approach to the cervical spine for discectomy and fusion by the insertion of an autologous iliac-crest tricortical bone graft was first described by Robinson and Smith in 1955 [39]. In 1958, Cloward described a wide anterior cylindrical 
discectomy performed with a special reamer combined with anterior fusion by the insertion of autologous iliac bone graft of the same shape [13]. Several implants used to perform anterior interbody fusion were later described. Bagby et al. developed the first interbody fusion cage [2]. Cages of different shapes and materials are used to perform ACDF which, in some cases, could be associated with plate fixation $[8,11,12,17,20]$.

The aim of the current study was to determine whether an anterior cervical discectomy and fusion with a polyetheretherketone (PEEK) anatomical cervical cage filled with allograft bone to perform fusion could be effective for decompressing the spinal cord, recovering cervical sagittal alignment, and providing solid arthrodesis and relief from symptoms with minimal surgical risk.

\section{Materials and methods}

A retrospective clinical study of 25 patients affected by single-level degenerative pathology between C4 and C7 who had undergone ACDF, between 2007 and 2009 was performed. The inclusion criterion for this study was single-level degenerative cervical pathology. In the case of spondylosis, the diagnosis was made based on the cervical degenerative index [35]. Indication for surgery was cervical pain associated with intractable radioculopathy that did not respond to nonoperative (conservative) treatment for a period of at least six weeks, or demonstrating progressive neurologic deficit during a period of observation. Patients with fractures, infection, deformity, tumors, chronic systemic illnesses such as diabetes mellitus, rheumatoid arthritis, and neurodegenerative diseases, or those with disorders at more than one level were excluded from this study. No exclusion was made based on sex, age, or the intensity of the preoperative clinical signs. Before surgery, all patients had plain AP and lateral radiographs, a CT scan or an MRI scan of their cervical spine.

Surgery consisted of single-level anterior discectomy and interbody fusion. To perform the intervention, the patient was placed on a surgical bed in the supine position with the neck extended slightly; under general anesthesia, an anterior-oblique longitudinal approach was used, overlying the medial border of the sternocleidomastoid muscle at the level of the degenerated intervertebral disc. The trachea and esophagus were retracted medially and the neurovascular bundle with the sternocleidomastoid muscle laterally. After fluoroscopic confirmation of the affected level, a complete discectomy and decompression was performed. The cervical column was placed in physiologic lordosis with the help of a Caspar screw distractor; then a PEEK anatomical cervical cage was inserted into the intervertebral space. Before the insertion, the cage was filled with cancellous bone allograft chips which were provided by Bone Bank. The postoperative protocol included discharge 1 day after surgery with soft collar protection for 3 weeks. The rehabilitation program included transcutaneous electrical nerve stimulation therapy (TENS) and local gentle massage during this period. After 3 weeks, the patient was checked in the outpatient facility, the soft collar was removed, and light recovery of the cervical spine with a physiotherapist was advised $[8,12,13,15$, 17, 18, 22, 29].

The clinical findings were assessed using the Neck Disability Index (NDI) [38, 46] and the Visual Analog Scale (VAS) [41] both pre- and postoperatively. At the last follow-up, the outcomes were rated according to Odom's criteria as excellent, good, fair, or poor, depending on the resolution, improvement, or persistence of preoperative symptoms (Table 1) [34]. At 6 months and at the last follow-up, the fusion was graded by assessing the radiographs as poor, average, good, or excellent. Fusion was confirmed by the presence of continuous trabecular bone bridges in at least one of the following locations: anterior, within, or posterior to the cage. The absence of such bridges or the presence of an anterior-posterior discontinuation was classified as nonfusion [37]. Cervical spine alignment was evaluated by sagittal segmental alignment (SSA) and sagittal alignment of the cervical spine (SACS) on lateral radiographs, preoperatively, 6 months postoperatively, and at the last follow-up (Fig. 1) [1, 15, 16].

All patients had a minimum 2 years of follow-up.

The study conforms to the Declaration of Helsinki as revised in 2008 and was approved by the institutional committee for medical ethics. All patients provided informed written consent.

\section{Results}

A total of 25 patients ( 3 female, 22 male) with a mean age of 42 (aged between 33 and 60 years) underwent ACDF through the use of PEEK anatomical cages filled with

Table 1 Classification of outcome according to Odom's criteria

\begin{tabular}{ll}
\hline Excellent & All preoperative symptoms relieved; abnormal findings improved \\
Good & Minimal persistence of preoperative symptoms; abnormal findings unchanged or improved \\
Fair & Definite relief of some preoperative symptoms; other symptoms unchanged or slightly improved \\
Poor & Symptoms and signs unchanged or exacerbated \\
\hline
\end{tabular}


Fig. 1 a Postoperative sagittal segmental alignment (SSA) angle, and $\mathbf{b}$ postoperative sagittal alignment of the cervical spine (SACS) angle

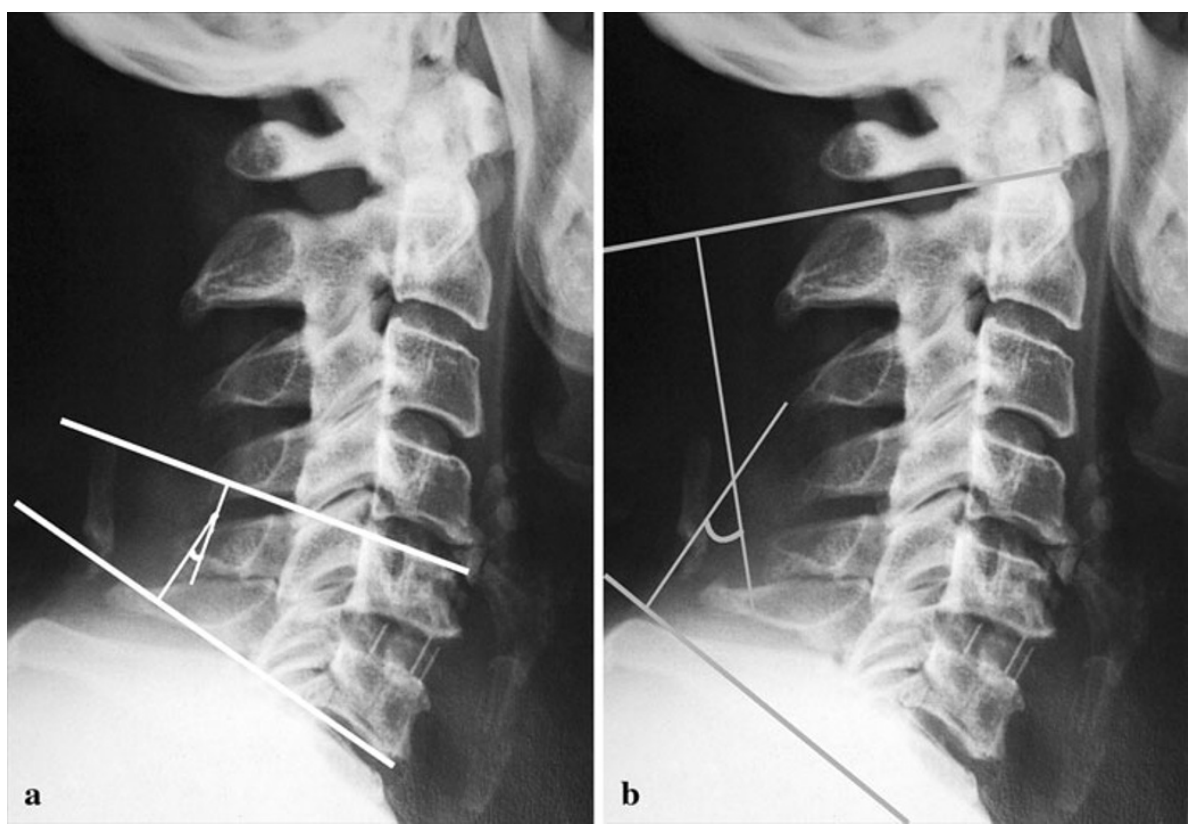

allograft bone. The operative levels were $\mathrm{C} 4-\mathrm{C} 5$ in 5 patients (20\%), C5-C6 in 12 patients (48\%), and C6-C7 in 8 patients $(32 \%)$. Twenty-two patients $(88 \%)$ presented with radiculopathy due to cervical disc herniation and 3 patients $(12 \%)$ due to cervical spondylosis. Twenty patients were discharged the day after surgery; 5 patients remained in the hospital for more than 2 days, including 3 for sustained postoperative pain and 2 with suspected postsurgical hematoma. All 5 of these patients were discharged without any complications 3 days after surgery.

The average NDI preoperatively was 34 (range 31-50), at 6 months it was 13 (range 3-22), and at the latest followup it was 10 (range 0-22). The mean preoperative VAS was 7 (range 4-10); the mean postoperative VAS at latest follow-up was 3 (range 0-5). The Neck Disability Index and Visual Analog Scale scores had both improved significantly in all patients by the last follow-up.

Odom's criteria for grading relief from symptoms was applied at the last follow-up. Nine patients (36\%) presented with an excellent clinical outcome, 11 good (44\%), 5 fair $(20 \%)$, and no patient presented a poor outcome. Twenty patients $(80 \%)$ showed clear relief from preoperative symptoms with subsequent functional improvement.

The mean time taken to achieve a grading of at least good radiographic signs of fusion in our study was 5 months (range 3-10). Good or excellent fusion was achieved in all patients within 10 months.

Preoperatively, the average SSA was $0.2^{\circ} \pm 2.2$, and the average SACS $15.8^{\circ} \pm 3.8$. As seen in the radiographs taken 6 months postoperatively, the average SSA was $1.8^{\circ} \pm 3.8$ and the average $\operatorname{SACS} 20.9^{\circ} \pm 5.8$. At last follow-up, the average SSA was $1.6^{\circ} \pm 4.6$ and the average SACS $18.5^{\circ} \pm 6.0$.

All patients had healed uneventfully with good results by the 2-year follow-up. No serious complicationsincluding deaths, reoperation, neurological damage (permanent or temporary), Horner's syndrome, pseudarthrosis, hardware failure, infection, and thrombosis-were seen.

All patients were permitted to return to light work by 4 weeks, and were allowed to perform heavier work and sports within 2-3 months after surgery.

There were no statistically significant differences in sex and age distribution.

\section{Discussion}

Anterior cervical discectomy and decompression with interbody fusion can be a good surgical choice when conservative treatment for cervical disc herniation or cervical spondylosis fails [7, 13, 15, 40]. Although tricortical autograft harvested from the iliac crest as interbody fusion material can provide satisfactory clinical results and fusion rates $[15,25]$, complication rates at the donor site are around $20 \%$ [42, 43], and could be a potential disadvantage of this technique. Interbody cages provide initial stability and, by filling the disc space, require less structural bone graft and consequently reduce the morbidity associated with autogenous bone graft harvesting [2, 23, 27, 42]. Different types of cages are available to perform ACDF, including titanium cages, carbon fiber reinforced polymer 
(CFRP) cages, and polyetheretherketone (PEEK) cages. Donor site complications can be omitted by making use of all of these cage types. Titanium cages can provide mechanical support, initial disc height maintenance, and restoration of sagittal lordosis; however, unfavorable outcomes were reported in some studies [11, 20, 33]. Kolstad et al. [27] reported several unfavorable outcomes following radiographic parameter analysis after ACDF using a cylindrical titanium cage. In another study, subsidence or migration of the titanium cage were observed, resulting in disc height collapse and kyphotic deformity [32]. Furthermore, metallic cages are radioopaque, which prevents clear observation of trabecular bone formation and of radiographic fusion signs. Carbon fiber cages (CFC) can be safe and effective, and can lead to restoration of segmental alignment and solid fusion [31, 45]. However, high rates of subsidence have been reported following ACDF using CFC (29.2\%) in some studies [4].

The absence of cytotoxicity and mutagenicity were demonstrated for a polyetheretherketone (PEEK) cage in an in vitro study [26]. With biocompatible, nonabsorbable, and corrosion-resistant abilities, the PEEK cage is thought to be a safe biomaterial spacer for spine surgery [44]. Moreover, the modulus of elasticity of PEEK is similar to that of bone [47]. This distinguishing feature is thought to be able to prevent cage subsidence induced by metallic cages. In an in vitro biomechanical study, the stiffness of the PEEK cage was statistically higher than that of the normal motion segment in flexion. The volume-related stiffness of the PEEK cage was higher than that of iliac bone in all directions. These results show that polyetheretherketone could be manufactured as the optimal interbody spacer, providing an adequate volume for bone refilling and immediate mechanical stability in ACDF [19, 30]. The PEEK cage is radiolucent and allowing the surgeon to better evaluate fusion status on radiographs or CT scans. In our series, all 25 patients (100\%) achieved good solid fusion within 10 months (mean 5 months) using a PEEK cage filled with cancellous allograft bone chips. These results confirm those of other studies $[28,30]$. In addition to a high fusion rate, successful treatment depends on the maintenance of interspace height and segmental angle [16, 25, 30]. Sagittal segmental alignment and sagittal alignment of the whole cervical spine are good indicators of the efficacy of anterior cervical discectomy and interbody fusion [16]. Comparison between preoperative and postoperative SSA and SACS demonstrated the efficacy of our technique for correcting cervical sagittal alignment when degenerative changes produce cervical spine straightening or cervical kyphosis. SSA and SACS angles measured at last follow-up demonstrate a slight loss of correction in comparison with the 6 month postoperative angles, but these changes were not significant, suggesting that the correction obtained with surgery was maintained even after 2 years.
Good or excellent results according to Odom's criteria in $80 \%$ of patients and significant improvements in the VAS and NDI assessments at last follow-up demonstrate that ACDF can be considered a good and effective technique for treating patients suffering from degenerative cervical pathology, and can improve the quality of life at short- and long-term follow-up.

The restoration of segmental alignment in lordosis with high rates of fusion in association with minimal surgical risk in this group of patients, while avoiding the complication of donor site bone graft harvesting, encourages the authors to use this technique more widely.

In conclusion, in order to reduce pain in and improve the quality of life of patients with degenerative cervical disc disease, disc herniation or cervical spondylosis where conservative treatment has failed, anterior cervical discectomy and interbody fusion using PEEK anatomical cervical cages can be an effective and low-risk technique. Filling the cages with allograft bone provides a good grade of fusion and solid arthrodesis. Our technique for ACDF with a PEEK anatomical cervical cage allows decompression of the spinal cord and nerve roots in combination with interbody fusion to provide segmental alignment in lordosis and solid arthrodesis with minimal surgical risk.

\section{Conflict of interest None.}

Open Access This article is distributed under the terms of the Creative Commons Attribution License which permits any use, distribution and reproduction in any medium, provided the original author(s) and source are credited.

\section{References}

1. Anakwenze OA, Auerbach JD, Milby AH, Lonner BS, Balderston RA (2009) Sagittal cervical alignment after cervical disc arthroplasty and anterior cervical discectomy and fusion: results of a prospective, randomized, controlled trial. Spine (Phila Pa 1976) 34(19):2001-2007

2. Bagby GW (1988) Arthrodesis by the distraction-compression method using a stainless steel implant. Orthopedics 11:931-934

3. Bailey RW, Badgley CE (1960) Stabilization of the cervical spine by anterior fusion. J Bone Joint Surg Am 42:565-594

4. Bartels RH, Donk RD, Feuth T (2006) Subsidence of stand-alone cervical carbon fiber cages. Neurosurgery 58(3):502-508; discussion $502-508$

5. Bartolozzi P, Salvi M (1992) Anterior surgery of the lower cervical spine. Chir Organi Mov 77:81-85

6. Benini A, Krayenbühl H, Brüderl R (1982) Anterior cervical discectomy without fusion. Microsurgical technique. Acta Neurochir (Wien) 61:105-110

7. Bohlman HH, Emery SE, Goodfellow DB, Jones PK (1993) Robinson anterior cervical discectomy and arthrodesis for cervical radiculopathy. J Bone Joint Surg Am 75:1298-1307

8. Bridwell KH, Dewald RL (1997) The textbook of spinal surgery, 2nd edn. Lippincott-Raven, Philadelphia, pp 227-242, 1373 1396 
9. Buchowski JM, Liu G, Bunmaprasert T, Rose PS, Riew KD (2008 May) Anterior cervical fusion assessment: surgical exploration versus radiographic evaluation. Spine (Phila $\mathrm{Pa}$ 1976) 33(11):1185-1191

10. Cauthen JC, Kinard RE, Vogler JB, Jackson DE, DePaz OB, Hunter OL, Wasserburger LB, Williams VM (1998) Outcome analysis of noninstrumented anterior cervical discectomy and interbody fusion in 348 patients. Spine (Phila $\mathrm{Pa}$ 1976) 23:188-192

11. Chou YC, Chen DC, Hsieh WA, Chen WF, Yen PS, Harnod T, Chiou TL, Chang YL, Su CF, Lin SZ, Chan SY (2008) Efficacy of anterior cervical fusion: comparison of titanium cages, polyetheretherketone (PEEK) cages and autogenous bone grafts. J Clin Neurosci 15(11):1240-1245

12. Clark Charles R (1998) The cervical spine, 3rd edn. LippincottRaven, Philadelphia

13. Cloward RB (1958) The anterior approach for removal of ruptured cervical disks. J Neurosurg 15:602-617

14. Edwards CC II, Heller JG, Silcox DH III (2000) T-saw laminoplasty for the management of cervical pondylotic myelopathy. Spine (Phila Pa 1976) 25:1788-1794

15. Faldini C, Leonetti D, Nanni M, Di Martino A, Denaro L, Denaro V, Giannini S (2010) Cervical disc herniation and cervical spondylosis surgically treated by Cloward procedure: a 10 -yearminimum follow-up study. J Orthop Traumatol 11(2):99-103

16. Faldini C, Pagkrati S, Leonetti D, Miscione MT, Giannini S (2011) Sagittal segmental alignment as predictor of adjacentlevel degeneration after a Cloward procedure. Clin Orthop Relat Res 469(3):674-681

17. Fransen P (2010) A simplified technique for anterior cervical discectomy and fusion using a screw-plate implanted over the Caspar distractor pins. Acta Orthop Belg 76(4):546-548

18. Frymore JW (1991) The adult spine-principles and practice. Raven, New York, pp 907-1014

19. Gu YT, Jia LS, Chen TY (2007) Biomechanical study of a hat type cervical intervertebral fusion cage. Int Orthop 31(1):101-105

20. Hauerberg J, Kosteljanetz M, Bøge-Rasmussen T, Dons K, Gideon P, Springborg JB, Wagner A (2008) Anterior cervical discectomy with or without fusion with ray titanium cage: a prospective randomized clinical study. Spine (Phila Pa 1976) 33(5):458-464

21. Herkowitz HN, Kurz LT, Overholt DP (1990) Surgical management of cervical soft disc herniation. Spine (Phila $\mathrm{Pa}$ 1976) 15:1027-1031

22. Hirabayashi K, Watanabe K, Wakano K, Suzuki N, Satomi K, Ishii Y (1983) Expansive open-door laminoplasty for cervical spinal stenotic myelopathy. Spine (Phila Pa 1976) 8:693-699

23. Jacobs W, Willems PC, Kruyt M, van Limbeek J, Anderson PG, Pavlov P, Bartels R, Oner C (2011) Systematic review of anterior interbody fusion techniques for single- and double-level cervical degenerative disc disease. Spine (Phila Pa 1976) 36(14):E950E960

24. Kambin P (1980) Anterior cervical fusion using vertical selflocking T-graft. Clin Orthop Relat Res 153:132-137

25. Kao FC, Niu CC, Chen LH, Lai PL, Chen WJ (2005) Maintenance of interbody space in one- and two-level anterior cervical interbody fusion: comparison of the effectiveness of autograft, allograft, and cage. Clin Orthop 430:108-116

26. Katzer A, Marquardt H, Westendorf J, Wening JV, von Foerster G (2002) Polyetheretherketone-cytotoxicity and mutagenicity in vitro. Biomaterials 23(8):1749-1759

27. Kolstad F, Nygaard ØP, Andresen H, Leivseth G (2010) Anterior cervical arthrodesis using a "stand alone" cylindrical titanium cage: prospective analysis of radiographic parameters. Spine (Phila Pa 1976) 35(16):1545-1550
28. Kulkarni AG, Hee HT, Wong HK (2007) Solis cage (PEEK) for anterior cervical fusion: preliminary radiological results with emphasis on fusion and subsidence. Spine J 7(2):205-209

29. Lang J (1993) Clinical anatomy of the cervical spine. Thieme, New York

30. Liao JC, Niu CC, Chen WJ, Chen LH (2008) Polyetheretherketone (PEEK) cage filled whith cancellous allograft in anterior cervical discectomy and fusion. Int Orthop 32(5):643-648

31. Marotta N, Landi A, Tarantino R, Mancarella C, Ruggeri A, Delfini R (2011) Five-year outcome of stand-alone fusion using carbon cages in cervical disc arthrosis. Eur Spine J 20(Suppl 1):S8-S12

32. Niu CC, Chen LH, Lai PL, Fu TS, Chen WJ (2005) Trapezoidal titanium cage in anterior cervical interbody fusion: a clinical experience. Chang Gung Med J 28(4):212-221

33. Niu CC, Liao JC, Chen WJ, Chen LH (2010) Outcomes of interbody fusion cages used in 1 and 2-levels anterior cervical discectomy and fusion: titanium cages versus polyetheretherketone (PEEK) cages. J Spinal Disord Tech 23(5):310-316

34. Odom GL, Finney W, Woodhall B (1958) Cervical disc lesions. J Am Med Assoc 166:23-28

35. Ofiram E, Garvey TA, Schwender JD, Denis F, Perra JH, Transfeldt EE, Winter RB, Wroblewski JM (2009) Cervical degenerative index: a new quantitative radiographic scoring system for cervical spondylosis with interobserver and intraobserver reliability testing. J Orthop Traumatol 10(1):21-26

36. Ofiram E, Garvey TA, Schwender JD, Wroblewski JM, Winter RB (2009) Cervical degenerative changes in idiopathic scoliosis patients who underwent long fusion to the sacrum as adults: incidence, severity, and evolution. J Orthop Traumatol 10(1):27-30

37. Pechlivanis I, Thuring T, Brenke C, et al. (2011) Non-fusion rates in anterior cervical discectomy and implantation of empty polyetheretherketone cages. Spine (Phila Pa 1976) 36(1):15-20

38. Pollard CA (1984) Preliminary validity study of the pain disability index. Percept Mot Index 59:974

39. Robinson RA, Smith G (1955) Anterolateral cervical disc removal and interbody fusion for cervical disc syndrome. Bull Johns Hopkins Hosp 96:223-224

40. Romanò CL, Romanò D, Bonora C, Mineo G (2009) Pregabalin, celecoxib, and their combination for treatment of chronic lowback pain. J Orthop Traumatol 10(4):185-191

41. Scott J, Huskinsson EC (1976) Graphic representation of pain. Pain 2:175-184

42. Siddiqui AA, Jackowski A (2003) Cage versus tricortical graft for cervical interbody fusion. A prospective randomised study. J Bone Joint Surg Br 85(7):1019-1025

43. Silber JS, Anderson DG, Daffner SD, Brislin BT, Leland JM, Hilibrand AS, Vaccaro AR, Albert TJ (2003) Donor site morbidity after anterior iliac crest bone harvest for single-level anterior cervical discectomy and fusion. Spine (Phila Pa 1976) 28:134-139

44. Toth JM, Wang M, Estes BT, Scifert JL, Seim HB III, Turner AS (2006) Polyetheretherketone as a biomaterial for spinal applications. Biomaterials 27(3):324-334

45. Van der Haven I, Van Loon PJ, Bartels RH, Van Susante JL (2005) Anterior cervical interbody fusion with radiolucent carbon fiber cages: clinical and radiological results. Acta Orthop Belg 71(5):604-609

46. Vernon H, Mior S (1991) The neck disability index: a study of reliability and validity. J Manipulative Physiol Ther 14(7):409415

47. Wenz LM, Merritt K, Brown SA, Moet A, Steffee AD (1990) In vitro biocompatibility of polyetheretherketone and polysulfone composites. J Biomed Mater Res 24(2):207-215 